\title{
The importance of hemodynamic considerations in essential hypertension
}

\begin{abstract}
Hypertension is a major risk factor for cardiovascular morbidity and mortality. Antihypertensive therapy consistently reduces complications from stroke and congestive heart fallure, whereas benefits from the treatment of ischemic heart disease events are variable. Several plausible explanations, including hemodynamic hypotheses, have been put forth to account for the failure of treatment to more favorably influence mortality from ischemic heart disease. The effect of hypertension on coronary heart disease is probably much more complex than a simple elevation of arterial pressure. Some of these complexities include the potential separate risks of high total peripheral resistance, high cardlac output, increased myocardial power that reflects pressure times flow, and several structural and functional vascular changes. These factors may act in concert to unfavorably alter the balance between myocardial oxygen supply and demand. Several of these factors will be highlighted in an attempt to offer alternative or adjunctive pathophyslologic examinations for the high-risk subgroups of obesity and the failure of antihypertensive therapy to normalize the rate of coronary heart disease events. (AM HEART J 1988;116:594.)
\end{abstract}

Brent Egan, MD, and Robert Schmouder, MD Ann Arbor, Mich.

Epidemiologic data provide evidence that elevated arterial blood pressure is associated with a significantly higher incidence of cardiovascular complications, including myocardial infarction..$^{1,2}$ Pharmacologic lowering of arterial pressure reduces total cardiovascular morbidity and mortality in hypertensive patients. ${ }^{3-6}$ Although the overall event rate is reduced, specific ischemic cardiac events are not consistently prevented. ${ }^{7}$ Numerous plausible explanations have been provided by various experts to account for this major shortcoming in several treatment trials (Table I).

This review focuses predominantly on the potential role of both early and late hemodynamic variables, including total peripheral (systemic) vascular resistance* (TPR) and cardiac output (CO), as well as their product, mean arterial (blood) pressure $\dagger$

From the Division of Hypertension, University of Michigan Medical Center.

Reprint requests: Brent Egan, MD, Division of Hypertension, University of Michigan Medical Center, 3918 Taubman Center, Ann Arbor, MI 481090356.

- Total systemic resistance (TSR) in arbitrary units is equivalent to mean blood pressure divided by cardiac output (CO). Total peripheral resistance (TPR) equals mean arterial pressure minus mean right atrial pressure divided by $\mathrm{CO}$. Since right atrial pressure is generally 0 to $4 \mathrm{~mm} \mathrm{Hg}$ in most

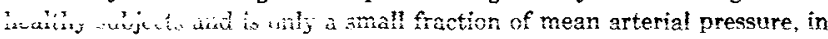
practice there is little difference between TPR and TSR. ${ }^{8}$

tMean arterial pressure (MAP, $\mathrm{mm} \mathrm{Hg}$ ) implies a value derived from integration of the area under the directly measured arterial pulse-wave form. Mean blood pressure (MBP, $\mathrm{mm} \mathrm{Hg}$ ) implies a calculated value derived from noninvasively measure systolic and diastolic blood pressure.
(MAP), on morbidity and mortality from coronary heart disease. Although the review is based on a wealth of physiologically sound experimental observations, some less recognized pathophysiologic concepts are explored in an attempt to more fully account for incompletely explained epidemiologic data. The data include not only the failure of antihypertensive therapy to normalize the excessive incidence of coronary artery disease, but also the excessive cardiac risk accompanying borderline hypertension and obesity, particularly in younger men.

\section{HEMODYNAMIC CONSIDERATIONS}

Peripheral vascular resistance. Several observations suggest the predominant importance of TPR in explaining the cardiac complications associated with hypertension. First, increased resistance to blood flow is the hemodynamic hallmark of hypertension. ${ }^{9,10}$ This conclusion is based on a continuously fixed pressure and constant flow model of circulation in which MAP $=\mathrm{CO} \times \mathrm{TPR}$. However, the power generator for the cardiovascular system, the heart, is pulsatile. In a pulsatile system, the forces opposing ventricular ejection of blood are more appropriately termed impedance. ${ }^{11}$ Unfortunately, the data needed to quantify impedance require considerably more sophisticated measurement techniques than those needed to obtain data for the calculation of TPR. Despite the limitations, the simpler steady-state pressure-flow paradigm has 
provided a useful conceptual framework for interpreting innumerable hemodynamic studies and will serve as the predominant model in this discussion.

As noted, in most persons with elevated arterial blood pressure, $\mathrm{CO}$ is within the normal range, whereas calculated resistance in absolute units is high. In hypertensive subjects with increased $\mathrm{CO}$, which occurs in a substantial proportion of borderline hypertensive and obese persons, ${ }^{12,13}$ the absolute resistance is normal. However, the resistance in relative terms is higher at any specified level of $\mathrm{CO}$ for those with higher arterial pressure. ${ }^{14}$

The importance of this apparently semantic argument is highlighted by hemodynamic data from studies on predominantly young men conducted in Ann Arbor. ${ }^{15}$ Subjects were divided into two groups on the basis of percentage over ideal body weight (IBW). One group was $<20 \%$ over IBW, whereas the other (obese) was $>20 \%$ over IBW. The obese subjects were characterized by higher blood pressure (BP) and CO but similar values for peripheral resistance in comparison to lean participants. Furthermore, in the overweight men BP was positively correlated to CO, but BP was not related to TPR. However, in the lean normotensive men, TPR decreased appropriately as CO increased so that BP remained normal. ${ }^{14}$ These data are consistent with previously reported information that $\mathrm{CO}$ is elevated similarly in overweight normotensive vs both borderline and overweight mild hypertensive subjects. ${ }^{13}$ Therefore the fundamental hemodynamic mechanism of elevated BP in both the lean borderline hypertensive and overweight borderline-mild subjects is an inappropriately high resistance for the prevailing level of blood flow. Additional studies performed in our laboratory indicate that an increase in vascular $\alpha$-adrenergic tone is an important factor in the relatively high resistance to blood flow in overweight people. ${ }^{16}$ These studies were conducted in young men who, as will be discussed, may be the group at greatest relative hemodynamic risk from being overweight.

Second, CO remains essentially unchanged across the spectrum of hypertension, from mild to severe levels. Consequently, a successive increase in TPR is the predominant explanation for the progression of hypertension. Therefore one could argue that the progressive rise in TPR is an important component of the higher cardiovascular complication rate in more severely hypertensive patients.

Third, antihypertensive compounds that initially reduce $C O$, namely, diuretics and $\beta$-blockers, have not consistently afforded primary prevention against coronary events, ${ }^{3-6}$ although exceptions have been noted. ${ }^{17}$ These comments are not intended to
Table I. Seven recommendations for improving the outcome of coronary artery disease in hypertensive patients
Lower BP more
Treat BP longer
Reduce BP less
Multiple risk factor intervention
Avoid electrolyte imbalances
Minimize SNS and RAS activity
Decrease TPR and not CO

SNS = sympathetic nervous system; RAS = renin-angiotensin system.

repudiate either the longer-term hemodynamic effects of diuretics or b-blockers, which, in fact, include reduction of TPR, ${ }^{18,19}$ or the beneficial effects of these compounds on stroke rate, ${ }^{5,6}$ but rather to suggest that pharmacologic approaches to reducing ischemic heart disease may be more hemodynamically complex than simply reducing arterial pressure.

Finally, a study of elderly men observed significantly lower cardiovascular mortality in overweight compared with lean hypertensive subjects. The lower absolute TPR in overweight hypertensive subjects was cited as one potential explanation for their more favorable cardiovascular outcome. ${ }^{20}$

Cardiac factors in determining the cardiovascular complication rate. If cardiovascular mortality were simply an inverse function of absolute TPR, then obese normotensive subjects would have the lowest cardiovascular complication rate, which is not the case. ${ }^{21,22}$ However, there is substantial evidence that obesity, which is accompanied by lower absolute values for TPR at any given level of arterial pressure, is an independent risk factor for higher rather than lower cardiovascular complication rates. ${ }^{23}$ Furthermore, borderline hypertension, which is characterized by relatively normal absolute values for TPR, ${ }^{12,13}$ is associated with a substantial increase in cardiovascular complications despite the minimal elevation of blood pressure..$^{24,25}$

Hemodynamically, borderline hypertension and obesity are both characterized by elevated absolute values for $\mathrm{CO}^{26}$ In other words, at any given level of afterload, which is roughly reflected by higher MAP, venous return or preload is also higher. ${ }^{27-29}$ Consequently, the heart is exposed to the double burden of both increased preload (venous return) and afterload (arterial pressure). ${ }^{29}$

The double hemodynamic load in overweight patients may explain some of the excessive incidence of heart disease. In the Framingham Study, persons $>20 \%$ over ideal weight, when compared with subjects $<20 \%$ overweight, were at threefold higher risk for subsequent hypertension. ${ }^{30}$ Moreover, obese sub- 
Table II. Hemodynamic power in various patient subgroups

\begin{tabular}{lcccc}
$\begin{array}{l}\text { Data }= \\
\text { mean } \pm S E\end{array}$ & $\begin{array}{c}\text { Lean } \\
N T\end{array}$ & $\begin{array}{c}\text { Lean } \\
B H T\end{array}$ & Obese & $H T$ \\
\hline No. & 236 & 129 & 70 & 39 \\
Age & $25 \pm 1$ & $26 \pm 1$ & $30 \pm 1$ & $40 \pm 1$ \\
$\%>$ IBW & $0 \pm 1$ & $4 \pm 1$ & $23 \pm 1$ & $15 \pm 2$ \\
SAP & $118 \pm 1$ & $132 \pm 1$ & $134 \pm 12$ & $150 \pm 13$ \\
DAP & $63 \pm 1$ & $73 \pm 1$ & $76 \pm 1$ & $85 \pm 2$ \\
CO (L/min) & $5.6 \pm 0.1$ & $6.7 \pm 0.1$ & $6.7 \pm 0.2$ & $5.8 \pm 0.1$ \\
Power & $74 \pm 1$ & $101 \pm 3$ & $103 \pm 34$ & $98 \pm 3$ \\
\multicolumn{5}{c}{ Results of ANOVA: $>p<0.05 ;=p>0.05$} \\
Age: HT $>$ obese $>$ BHT $=$ NT \\
\% IBW: Obese $>$ HT $>$ BHT $>$ NT \\
SAP: HT $>$ Obese $=$ BHT $>$ NT \\
DAP: HT $>$ Obese $=$ BHT $>$ NT \\
CO: Obese $=$ BHT $>$ HT $=$ NT \\
Power: Obese $=$ BHT $=$ HT $>$ HT
\end{tabular}

$\mathrm{SAP}=$ systolic arterial pressure, $\mathrm{mm} \mathrm{Hg} ; \mathrm{HT}=$ hypertensive; $\mathrm{DAP}=$ dia stolic arterial pressure, $\mathrm{mm} \mathrm{Hg}$; lean $<20 \%$ over IBW; obese $\geq 20 \%$ over IBW; $\mathrm{BHT}=$ borderline hypertensive; $\mathrm{ANOVA}=$ analysis of variance; power $=$ CO $\left(\mathrm{cm}^{3} / \mathrm{min}\right) \times$ MAP $\left(1333\right.$ dyne $\left./ \mathrm{cm}^{2}\right) \times 10^{-7}$ joules $/$ dyne $(\mathrm{cm})=$ joules $/ \mathrm{min}$

jects were at approximately 10 -fold higher risk for hypertensive cardiovascular disease (HCVD), which is defined as left ventricular hypertrophy by either chest radiography or electrocardiography.

Data from the Australian Heart Foundation Study attributed as much as $30 \%$ of hypertension in men and women between 25 and 64 years of age to being overweight. ${ }^{31}$ However, within the subgroup of men less than 45 years old, as much as $60 \%$ of hypertension was explained by weight. Therefore from a hemodynamic viewpoint, overweight younger men may be at the greatest relative risk. Consequently, an analysis of hemodynamic data in this high risk subgroup, as will be discussed, may prove enlightening.

The potential importance of cardiac power. As previously noted, the incidence of HCVD in overweight subjects substantially exceeds that predicted from the higher rates of hypertension. Consequently, it is possible that in obesity the double cardiac burden of both increased preload and afterload offers a more satisfactory explanation than pressure levels alone for the excessive HCVD. A prerequisite for initial examination of this hypothesis is a quantitative expression of that dual cardiac load.

Preload or venous return is reflected quite precisely by $\mathrm{CO}$, since over time venous return and $\mathrm{CO}$ must be equal. Afterload is approximated by nigner MAP. In the constant pressure-flow model of the circulatory system, the power the heart generates to overcome its load equals the product of $\mathrm{CO}$ and
MAP. ${ }^{11}$ Therefore cardiac power reflects components of both preload and afterload. Cardiac power is also a more comprehensive term than the two more commonly used measures: stroke work and pressure-rate product. Stroke work does not account for the frequency (heart rate) of work, whereas pressure-rate product does not include stroke volume.

An index of cardiac power was calculated from baseline data obtained in supine volunteers who participated in hemodynamic studies conducted in the Hypertension Division at Ann Arbor. One adjustment was made in the constant pressure-flow model in the calculations. Since the left ventricle generates $\mathrm{CO}$ only during systole, calculated mean systolic arterial pressure rather than MAP was used in the cardiac power calculation. Because left atrial pressure data were unavailable, no adjustment was made for this variable in the computation. Thus cardiac (left ventricular) power ${ }^{32}$ was determined by the product of $\mathrm{CO}$, as measured by indocyanine green dye dilution, and mean systolic pressure, calculated from systolic and diastolic pressures measured directly from a brachial artery catheter. The results are summarized in Table II. As shown, cardiac power was substantially higher in lean borderline hypertensive and obese subjects compared with lean normotensive persons. In fact, power in these two conditions was virtually identical to levels calculated in older subjects with established essential hypertension.

Consequently, cardiac power rather than BP may serve as a more useful predictor of age-adjusted cardiac complications in borderline hypertension and obesity. This hypothesis requires confirmation but may provide a partial hemodynamic basis for the independent contributions of overweight to cardiovascular disease. ${ }^{21}$ Indirect confirmation for the potential use of cardiac power is provided by data obtained in children from Muscatine, Iowa. ${ }^{33}$ Children with BP levels in the upper quintile had a higher left ventricular mass index compared with their cohorts with BP levels in the lowest quintile. Within the upper quintile of $\mathrm{BP}$, children with higher $\mathrm{COs}$ (greater cardiac power) had the highest values for left ventricular mass.

Vascular Factors (structural vascular abnormalities). In the development of hypertension in the spontaneously hypertensive rat, a progression of structural vascular changes occurs. In 6- to 8-week-old spontaneousiy nyperiensive rats, capillary rarefaction is followed by functional arteriolar rarefaction at 12 to 14 weeks and finally structural arteriolar rarefaction at 16 to 18 weeks. ${ }^{34}$ Similarly, capillary rarefaction 
Table III. Known and postulated effects of the hypertensive process on the balance between myocardial oxygen supply and demand

\begin{tabular}{ll}
\hline Increased demand & Decreased supply \\
\hline$\uparrow \mathrm{BP}$ & $\uparrow \mathrm{HR}$ \\
$\uparrow \mathrm{HR}$ & Functional vascular \\
& changes \\
$\uparrow$ Contractility (early) & $\lceil$ Response to hypoxia \\
& $\uparrow \mathrm{EDV}$ \\
$\uparrow$ Cardiac power & $\uparrow$ Myogenic tone \\
$\uparrow \mathrm{LVMM}$ & $\uparrow \alpha$-Tone \\
Increased Supply & Structural vascular changes \\
& Rarefaction \\
& $\uparrow$ Wall:lumen \\
$\uparrow \mathrm{DBP}$ & Diastolic dysfunction \\
& Coronary atherosclerosis \\
& (accelerated by HTN)
\end{tabular}

HR $=$ heart rate; $\mathrm{DBP}=$ diastolic blood pressure; $\mathrm{EDV}=$ ends diastolic volume; HTN = hypertension; LVMM = left ventricular muscle mass.

has been reported in borderline hypertensive humans, ${ }^{35}$ evidence for arteriolar rarefaction has been observed in established human hypertensives. ${ }^{36}$ Interestingly, in borderline hypertensive subjects, the degree of rarefaction was not significantly related to arterial pressure, but rather was inversely related to $\mathrm{CO}$. In other words, borderline hypertensive patients with the highest $\mathrm{CO}$ displayed the greatest degree of capillary rarefaction..$^{35}$ In contrast, elevated BP induces medial hypertrophy, ${ }^{35}$ which predominantly involves arteries and larger arterioles. $^{37}$

Functional vascular abnormalities. One of the most widely reported and recognized abnormalities of the arterial circulation in hypertension is an impaired vasodilator response to ischemia. ${ }^{38-40}$ The reduced vasodilator response to 10 minutes of regional ischemia partially reflects structural vascular changes. $^{38-40}$ However, hypertensive vessels may maintain higher tone under some conditions, in part through decreased sensitivity to hypoxemia or its metabolic consequences. ${ }^{41}$ Enhanced vasodilator responses to both calcium channel blockade ${ }^{42,43}$ (an index of myogenic tone) and $\alpha$-receptor antagonists $^{44,45}$ (an index of vascular $\alpha$-tone) comprise other well-documented functional abnormalities of hypertensive vessels. Explanations for these functional abnormalities are numerous, but agreement on specific mechanisms is not uniform. A hypothetic schematic depicting the causes and effects of vascular changes in the development and progression of hypertension is shown in Fig. 1.

Potential relationship of the structural and functional vascular changes to ischemic heart disease. Dimin-

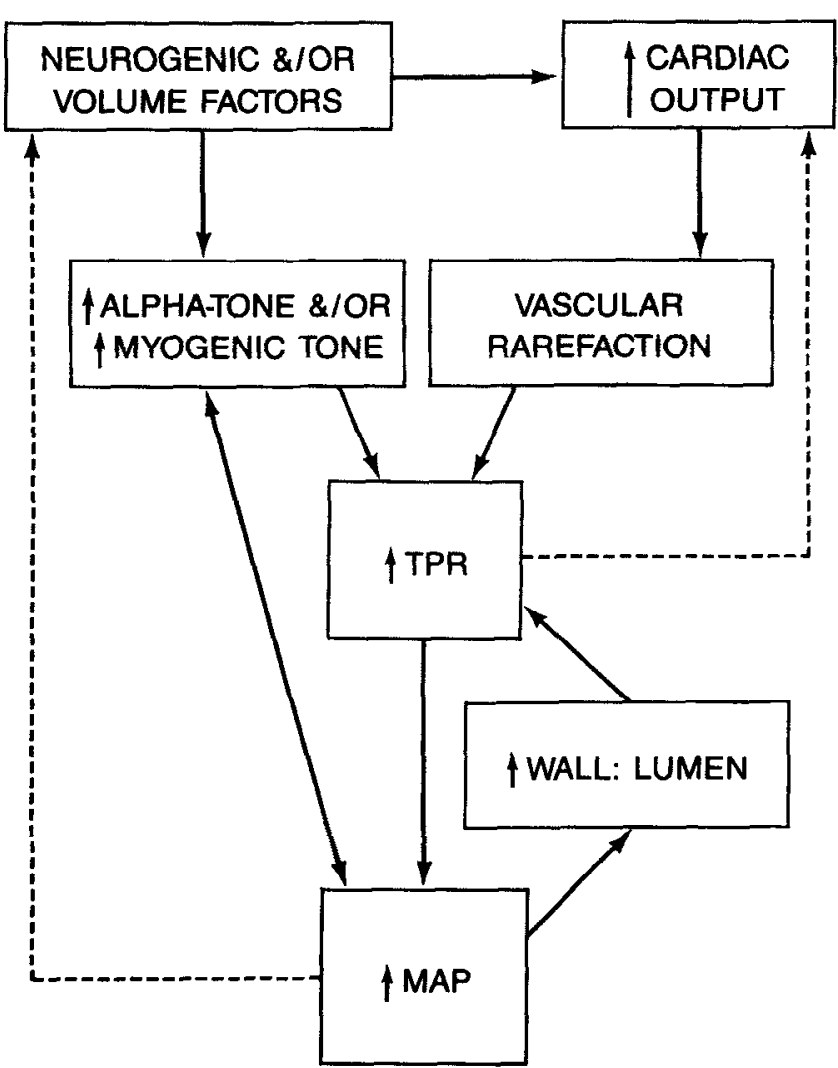

Fig. 1. Proposed causes and effects of vascular changes in hypertension.

ished coronary vasodilator reserve has been demonstrated in the hearts of hypertensive men and animals subjected to pressure overload from either systemic hypertension or aortic stenosis. ${ }^{46}$ The impaired vasodilator reserve in hypertensive subjects likely reflects some of the functional and structural vascular changes previously noted. More specifically, vascular rarefaction and an increased wall-lumen ratio (concentric vascular hypertrophy) could provide a structural component to the diminished flow reserve. Rarefaction, even in the presence of normal total coronary flow levels, would increase the mean diffusion distance from individual capillaries to adjacent myocardial cells. ${ }^{47}$ Thus the myocardial cells at greatest distance from nutrient supply would be at increased risk for ischemia. Impaired vasodilator responses to ischemia ${ }^{41}$ would further exacerbate the effects of the structural and functional vascular changes. An increased vascular wall-lumen ratio ${ }^{37}$ although not documented in the coronary circulation, ${ }^{48}$ would accentuate vascular responses to all vasoconstrictor stimuli. ${ }^{37,38,49,50}$ In other words, when compared with a normal vessel, equivalent degrees of smooth muscle contraction in a vessel characterized by greater wall thickness in 
relationship to luminal radius produce greater compromise of the lumen. ${ }^{37}$ Since resistance varies inversely with the fourth power of the radius, ${ }^{51}$ the increased wall-lumen ratio would enhance vascular resistance responses to all vasoactive compounds. ${ }^{38}$ The enhanced vasoconstrictor responsiveness would include that reflecting impaired endotheliumdependent vasodilation in hypertension..$^{52}$ More specifically, the vasoconstrictor effects of several compounds, including thrombin, serotonin, and catecholamines acting as $\alpha_{2}$-receptor agonists, are partially counterbalanced by endothelium-dependent vasodilation. ${ }^{53-55}$

The microvascular problems discussed previously would compound the adverse effects on myocardial perfusion of coronary macrovascular atherosclerosis, which is accelerated by hypertension. If the structural and functional abnormalities interact diabolically in the coronary circulation as postulated, then one can envision how these factors would, over time, produce ischemia-related events, including angina, infarction, arrhythmias, and cardiac decompensation. The multiple effects of the hypertensive process and the vascular changes in the balance between myocardial oxygen supply and demand are summarized in Table III. An extensive discussion of the separate risks of left ventricular hypertrophy exceeds the scope of this discussion, but the topic has been succinctly reviewed. ${ }^{56}$

\section{CONCLUSION}

The hemodynamic dysregulation that occurs in the development and progression of hypertension may contribute not only to elevated arterial blood pressure, but may also act in concert with the higher pressure levels to induce structural and functional cardiovascular changes. The anatomic and physiologic cardiovascular changes, which are not fully reversed by antihypertensive therapy, provide the substrate for subsequent complications. A greater understanding of the sequential hemodynamic pathophysiology of hypertension may permit the development of more effective treatment strategies. Although unproved, physiologically based treatment vs conventional approaches, which are targeted at correcting the underlying hemodynamic abnormalities in hypertension, may more effectively interrupt the sequence of events leading to cardiac morbidity and mortality.

\section{KEFERENCES}

1. Kannel WB, Dawber TR. Hypertension as an ingredient of a cardiovascular risk profile. Br J Hosp Med 1974;2:508.

2. Relationship of blood pressure, serum cholesterol, smoking habit, relative weight, and ECG abnormalities to incidence of major coronary events: final report of the pooling project, pooling project research group. J Chronic Dis 1978;31:201.

3. Veterans Administration Cooperative Study Group on Antihypertensive Agents. Effects of treatment on morbidity in hypertension. II. Results in patients with diastolic blood pressure averaging 90 through $114 \mathrm{~mm} \mathrm{Hg}$. JAMA 1970; 213:1143-52.

4. Hypertension Detection and Follow-up Program Cooperative Group. Five-year findings of the hypertension detection and follow-up program. I. Reduction in mortality of persons with high blood pressure, including mild hypertension. JAMA 1979;242:2562-71.

5. Report of the Management Committee. The Australian therapeutic trial in mild hypertenison. Lancet 1980; I: 1261-7.

6. Medical Research Council Working Party. MRC trial of treatment of mild hypertension: principal results. $\mathrm{Br}$ Med J 1985;291:97-104.

7. Fries ED. Should mild hypertension be treated? N Engl J Med 1982;309:306-9.

8. McDonald DA. Blood flow in arteries. 2nd ed. London: Arnold, 1974.

9. Freis ED. Hemodynamics of hypertension. Physiol Rev 1960;40:727-54.

10. Conway J. Hemodynamic aspects of essential hypertension in humans. Physiol Rev 1984;64:617-60.

11. Yin CP. Ventricular/vascular coupling. New York: SpringerVerlag, 1986.

12. Julius S,Esler M. Autonomic nervous cardiovascular regulation in borderline hypertension. Am $J$ Cardiol 1975;36:685-96.

13. Messerli FH, Christie B, DeCarvalho JGR, et al. Obesity and essential hypertension. Arch Int Med 1981;141:81-5.

14. Julius $S$, Conway J. Hemodynamic studies in patients with borderline blood pressure elevation. Circulation 1968;38: 282-8.

15. Egan BM, Schork NA, Julius S. Mechanism of inappropriately normal peripheral resistance in overweight men. Circulation 1987;76(suppl 2):209.

16. Egan BM, Schork NA. Increased vascular alpha-tone contributes to the inappropriately normal peripheral resistance in overweight men. Clin Res 1987;35:830A.

17. Hypertension Detection and Follow-up Program Cooperative Group. Effect of stepped-care treatment on the incidence of myocardial infarction and angina pectoris. Five-year findings of the hypertension detection and follow-up program. Hypertension 1984;6(suppl I):I198-I206.

18. Conway J, Lauwers P. Hemodynamic and hypotensive effects of long-term therapy with chlorothiazide. Circulation 1960; 21:21.

19. Colfer HT, Cottier C, Sanchez R, Julius S. Role of cardiac factors in the initial hypotensive action by beta-adrenoreceptor blocking agents. Hypertension 1984;6:145-51.

20. Barret-Connor $E$, Khaw KT. Is hypertension more benign when associated with obesity? Circulation 1985;72:53.

21. Lew EA, Garfinkel L. Variations in mortality by weight among 750,000 men and women. J Chronic Dis 1979;32:563.

22. McCue H Jr. The 1979 build and blood pressure study. In: Bostrom H, Ljungstedt N, eds. Medical aspects of mortality statistics. Stockholm: Almquist \& Wiksell International, 1981:182.

23. Hubert HB, Feinleib M, McNamara PM, Castelli WP. Obesity as an independent risk factor for cardiovascular disease: a 26-year follow-up of participants in the Framingham Heart Study. Circulation 1983;67:968-77.

24. Smith WM. Epidemiology of hypertension. Med Clin North Am 1977;61:467.

25. Kannel WB, Sorlie MS, Gordon T. Labile hypertension: a faulty concept? The Framingham Study. Circulation 1980;61:1183-7.

26. Messerli FH, Ventura HO, Reisin E, E, et al. Borderline 
hypertension and obesity: two prehypertensive states with elevated cardiac output. Circulation 1982;66:55-60.

27. Ellis CN, Julius $\mathrm{S}$. Role of central blood volume in hyperkinetic borderline hypertension. Br Heart J 1973;35:450-5.

28. Safar ME, Weiss YA, London CM, Frackowiak RD, Milliez PL. Cardiopulmonary blood volume in borderline hypertension. Clin Sci 1974;47:153-64.

29. Messerli FH, Sundgaard-Riise K, Reisin E, Dreslinski G, Dunn FG, Frohlich E. Disparate cardiovascular effects of obesity and arterial hypertension. Am J Med 1982;74:808-12.

30. Kannel WB, Brand N, Skinner JJ Jr, Dawber TR, McNamara PM. The relation of adiposity to blood pressure and development of hypertension. The Framingham study. Ann Intern Med 1967;48-59.

31. MacMahon SW, Blacket RB, Macdonald GJ, Hall W. Obesity, alcohol consumption, and blood pressure in Australian men and women. The National Heart Foundation of Australia risk factor prevalence study. J Hypertens 1984;2:85-91.

32. Sokolow M. Clinical cardiology, 3rd ed. Los Altos, California: Lange Medical Publishers, 1981.

33. Schieken RM, Clarke WR, Laur RM. Left ventricular hypertrophy in children with blood pressures in the upper quintile of the distribution. The Muscatine study. Hypertension $1981 ; 3: 669$.

34. Prewitt RL, Chen IIH, Dowell R. Development of microvascular rarefaction in the spontaneously hyperactive rat. Am J Physiol 1982;243:H243-51.

35. Sullivan JM, Prewitt RL, Joseph JA. Attenuation of the microcirculation in young patients with high-output borderline hypertension. Hypertension 1983;5:844-51.

36. Harper RN, Moore MA, Marr MC, Walls LE, Hutchins PM. Arteriolar rarefaction in the conjunctiva of human essential hypertensives. Microvasc Res 1978;16:369-72.

37. Folkow B, Grimby G, Thulesius $\mathbf{O}$. Adaptive structural changes of the vascular walls in hypertension and their relation to the control of the peripheral resistance. Acta Physiol Scand 1958;44:255-72.

38. Sivertsson $\mathbf{R}$. The hemodynamic importance of structural vascular changes in essential hypertension. Acta Physiol Scand Suppl 1970;343:1-56.

39. Conway J. A vascular abnormality in hypertension. A study of blood flow in the forearm. Circulation 1986;27:520-9.

40. Egan BM, Julius S. Vascular hypertrophy in borderline hypertension: relationship to blood pressure and sympathetic drive. Clin Exp Hypertens 1985;A7:243-55.

41. Walsh GM, Tsuchyia M, Cox AC, Tobia AJ, Frohlich ED. Altered hemodynamic response to acute hypoxemia in spontaneously hypertensive rats. Am J Physiol 1978;234:H275.
42. Robinson BF, Dobbs RJ, Bayley $\mathrm{S}$. Response of forearm resistance vessels to verapamil and sodium nitroprusside in normotensive and hypertensive men: evidence for a functional abnormality of vascular smooth muscle in primary hypertension. Clin Sci 1982;63:33-42.

43. Hulthen UL, Bolli P, Amann FW, Kiowski W, Buhler FR. Enhanced vasodilatation in essential hypertension by calcium channel blockade with verapamil. Hypertension 1982; 4(suppl II):II26-II31.

44. Amann FW, Bolli P, Kiowski W, Buhler FR. Enhanced alpha-adrenoreceptor-mediated vasoconstriction in essential hypertension. Hypertension 1981;3(suppl I):I119-23.

45. Egan BM, Panis R, Hinderliter A, Schork N, Julius S. Mechanism of increased alpha-adrenergic vasoconstriction in human essential hypertension. J Clin Invest 1987;80:812-7.

46. Marcus ML, Harrison DG, Chilian WM, et al. Alterations in the coronary circulation in hypertrophied ventricles. Circulation 1987;74(suppl I):I119-I25.

47. Anversa P, Ricci R, Olivetti G. Effects of exercise on the capillary vasculature of the rat heart. Circulation 1987; 75(suppl I):I12-8.

48. Kamal MF, Campbell ACP. Medical hypertrophy in the small intestinal arteries in systemic hypertension, renal and essential. J Pathol 1979;129:99-110.

49. Folkow B. Cardiovascular structural adaptation; its role in the initiation and maintenance of primary hypertension. Clin Sci 1978;55:3s-22s.

50. Egan BM, Panis R, Hinderliter A, Schork N. Vascular structure enhances regional resistance responses in mild hypertension. J Hypertens 1988;6:41-8.

51. Poiseiulle JLM. Recherches experimentales surle mouvement des liquides dans les tubes de tres petits diameters. Mem Savant Etragners 1846;9:433.

52. Lockette W, Otsuka Y, Carretero $O$. The loss of endotheliumdependent vascular relaxation in hypertension. Hypertension 1986;8(suppl II):II61-6.

53. Cohen RA, Shepherd JT, VanHoutte PM. Endothelium and asymmetrical responses of the coronary arterial wall. Am Physiol Soc 247 (Heart Circ Physiol 16):1984;H403-8.

54. Ku DD. Coronary vascular reactivity after acute myocardial ischemia. Science 1982;218:576.

55. Matsuda H, Kuon E, Holtz J, Busse R. Endotheliummediated dilations contribute to the polarity of the arterial wall in vasomotion induced by $\alpha_{2}$-adrenergic agonists. $\mathrm{J}$ Cardiovasc Pharmacol 1985;7:680-8.

56. Frohlich ED. Potential mechanisms explaining the risk of left ventricular hypertrophy. Am J Cardiol 1987;59:91A-7A. 